International Journal of Engineering \& Technology, $7(4.10)(2018) 602-604$
International Journal of Engineering \& Technology
SPC
Website: www.sciencepubco.com/index.php/IJET
Research paper

\title{
A Comparative Study of Experimental and Theoretical Ultrasonic Velocity of Binary Liquid Mixtures Using Mathematical Methods
}

\author{
A. Gayathri ${ }^{1}$, T. Venugopal ${ }^{1}$, K. Venkatramanan ${ }^{2, *}$ \\ ${ }^{l}$ Dept. of Mathematics, SCSVMV (Deemed University), Kanchipuram, India \\ ${ }^{2}$ Dept. of Physics, SCSVMV (Deemed University), Kanchipuram, India \\ *Corresponding author E-mail: kv@kanchiuniv.ac.in
}

\begin{abstract}
A comparative study of ultrasonic velocities of binary liquid mixtures such as O-cresol+carbon tetrachloride, anisicaldehyde+methylacetate, anisicaldehyde+ethylacetate, having industrial applications are analysed at temperature $303 \mathrm{~K}$ for different concentrations [0 to $1 \%$ ]. In the present study experimental values are taken from literature and there values are compared with theoretical values obtained by various mathematical equations such as Nomoto's relation, VandealVangeal formula, Impedance relation, Rao's specific relation. Thus, the present study reveals the nature of interaction between component molecules in the mixtures and enables us to identify a suitable mathematical model for predicting the ultrasonic velocity various binary liquid mixtures.
\end{abstract}

Keywords: Binary liquids; Impedance relation; Nomoto's relation; Rao Specific relation; Ultrasonic velocity; Vand-deal and Van-Geal.

\section{Introduction}

In recent years, there has been a continuous improvement in the experimental investigation of excess thermodynamic properties of liquid mixtures. Particularly, ultrasonic study of liquid mixtures has gained much importance in assessing the nature of molecular interactions present in the mixtures. Experimental and theoretical ultrasonic velocity studies in liquids and polymer solutions have been the subject of research in recent years. The experimental ultrasonic velocity values of O-Cresol with carbon tetrachloride, anisicaldehyde + methylacetate, anisicaldehyde + ethylacetate are compared with their theoretical values obtained by using various mathematical methods like Nomotto's Relation, Vandeal and Vangeal Relation, Impedance Relation and Rao's specific sound velocity. The most accurate mathematical method is identified using Average Percentage Error (APE).

\section{Methods and Materials}

The binary mixtures are prepared by dissolving O-Cresol with Carbon tetrachloride, anisicaldehyde with methylacetate and anisicaldehyde with ethylacetate to get desired concentrations. Magnetic stirrer [REMI make] was used for this purpose at a rate of $1000 \mathrm{rpm}$. Density values are measured using specific gravity method. The mass of the liquid was measured using a K-ROY make Electronic balance, with an accuracy of $\pm 0.001 \mathrm{gm}$. The ultrasonic velocity measurements are performed using Mitta make single frequency ultrasonic interferometer at $2 \mathrm{MHz}$ (F-81 model) (uncertainty $\pm 0.01 \mathrm{~m} / \mathrm{s}$ ).

\section{Results and Discussion}

\subsection{Evaluation of Ultrasonic velocity}

In recent years, measurement of ultrasonic velocity found extensive application in determining the physicochemical behavior of liquid mixtures. Theoretical evaluation of ultrasound velocity gives a better understanding of molecular arrangement in liquids [1-3]. In the present study, the experimental ultrasonic velocity values of $\mathrm{O}$-Cresol with carbon tetrachloride, anisicaldehyde + methylacetate, anisicaldehyde + ethylacetateare compared with their theoretical ultrasonic velocities by Nomotto's relation $\left(\mathrm{U}_{\mathrm{Nom}}\right)$ Vandeal Vangeal $\left(\mathrm{U}_{\mathrm{IMR}}\right)$ relation, Impedance relation $\left(\mathrm{U}_{\mathrm{IR}}\right)$ and Rao's specific sound velocity relation $\left(U_{R}\right)$ as given below.

\section{Nomotto's relation}

On assuming the additivity of molar sound velocity (R) and no volume change on mixing, Nomotto established the following relation for a liquid mixture.

$$
U_{N O M}=\left[\frac{X_{1} R_{1}+X_{2} R_{2}}{X_{1} V_{1}+X_{2} V_{2}}\right]^{3}
$$

Where, $\mathrm{R}$ is molar sound velocity, $\mathrm{X}_{1}$ and $\mathrm{X}_{2}$ are the mole fractions of $1^{\text {st }}$ and $2^{\text {nd }}$ components of the liquid mixture and $\mathrm{V}$ is molar volume. The molar sound velocity can be determined using the formula 
$R_{1}=\left(M_{1} / d_{1}\right) U_{1}^{1 / 3}$

$R_{2}=\left(M_{2} / d_{2}\right) U_{2}^{1 / 3}$

where, $\mathrm{M}_{1}$ and $\mathrm{M}_{2}$ are the effective molecular weight of the $1^{\text {st }}$ and $2^{\text {nd }}$ components, $d_{1}$ and $d_{2}$ are the densities of the $1^{\text {st }}$ and $2^{\text {nd }}$ components and $\mathrm{U}_{1}$ and $\mathrm{U}_{2}$ are the ultrasonic velocities of the $1^{\text {st }}$ and $2^{\text {nd }}$ components.

\section{Van Deal and Van Geal ideal mixing relation}

Van Deal and Van Geal proposed the following expression for the estimation of sound velocity $\mathrm{U}_{\text {IMR }}$ in an ideal mixture using the sound velocities in the pure components.

$U_{I M R}=\left[\frac{1}{\left(X_{1} M_{1}+X_{2} M_{21}\right)^{1 / 2}}\right]\left(\frac{1}{\left(\frac{X_{1}}{M_{1} U_{1}^{2}}+\frac{X_{2}}{M_{2} U_{2}^{2}}\right)^{1 / 2}}\right)$

where, $X_{1}$ and $X_{2}$ are the mole fractions of $1^{\text {st }}$ and $2^{\text {nd }}$ components of the liquid mixture, $\mathrm{M}_{1}$ and $\mathrm{M}_{2}$ are the effective molecular weight of the $1^{\text {st }}$ and $2^{\text {nd }}$ components, $d_{1}$ and $d_{2}$ are the densities of the $1^{\text {st }}$ and $2^{\text {nd }}$ components and $\mathrm{U}_{1}$ and $\mathrm{U}_{2}$ are the ultrasonic velocities of the $1^{\text {st }}$ and $2^{\text {nd }}$ components.

\section{Impedance relation}

Impedance relation is given by

$U=\frac{\sum X_{i} Z_{i}}{\sum X_{i} d_{i}}$

Where, $X_{i}, Z_{i}$ and $d_{i}$ and $Z_{i}=U_{i} d_{i}$ are the mole fractions of the liquid mixture, specific acoustical impedance of the liquid mixture and density of liquid mixture.

\section{Rao's specific relation}

The Rao's Specific Sound velocity relation for determination of ultrasonic velocity in binary liquid mixture can be given as

$$
U=\left(\sum X_{i} r_{i} d_{i}\right)^{3}
$$

Where, $r_{i}$ is the Rao's specific sound velocity and $Z_{i}$ is the acoustical impedance. Rao's specific sound velocity can be calculated using the relation

$r_{i}=U_{i}^{1 / 3} / d_{i}$

\subsection{Average Percentage Error}

The average percentage error of deviation is calculated by the following formula

$$
A P E=\frac{1}{n} \sum\left[\left(\frac{U_{\text {exp }}-U_{c a l}}{U_{\exp }}\right)\right] * 100
$$

The experimentally measured ultrasonic velocity and the estimated ultrasonic velocity from various mathematical models like Nomotto, Vandeal Vangeal, Impedance Relation and Rao's Specific Velocity Method for the binary liquid mixture O-Cresol with Carbon tetrachloride at five different concentrations at $303 \mathrm{~K}$ are presented in the Table 1. From Table 1, it is observed that the experimental values of ultrasonic velocity increases with increase in concentration. The molecular association is responsible for this increasing trend. Similar trend is observed in Nomotto relation method, Impedance relation and Rao's specific velocity method. The ultrasound velocities obtained from Nomotto's relation method and Rao's specific sound velocity values are almost same [4-6]. The limitations and approximations incorporated in these theories are responsible for the deviations of theoretical values from experimental values. Table 2 shows the variation of percentage of deviation with respect to the composition of O-Cresol with Carbon tetrachloride at $303 \mathrm{~K}$. In this system, it is understood that the percentage of deviation is more in Impedance relation (IMP) than Rao's specific relation (RAO) than Van-Deal and Vang-Geal (VV) than Nomotto's relation. i.e, IMP $>$ RAO $>V V>N O M$. In Nomotto's relation only negligible deviation to experimental values is observed when compared to other methods. The experimentally measured ultrasonic velocity and the estimated ultrasonic velocity from various mathematical models for the binary liquid mixture anisic aldehyde (AA) +methyl acetate (MA) at five different concentrations at $303 \mathrm{~K}$ are presented in the Table 2. From Table 3, it is observed that the experimental values of ultrasonic velocity increases with increase in concentration. The molecular association is responsible for this increasing trend. Similar trend is observed in Nomotto's relation method, Impedance relation and Rao's specific velocity method. The ultrasound velocities obtained from Nomotto's relation method and Rao's specific sound velocity values are almost same.

Table 1: Experimental and mathematical values of ultrasound velocity for O-cresol with Carbon tetrachloride

\begin{tabular}{|c|c|c|c|c|c|}
\hline Conc $(\%)$ & EXP & NOM & VV & RAO & IMP \\
\hline 0.0154 & 971 & 1190 & 1150 & 1183 & 1151 \\
\hline 0.0341 & 958 & 1289 & 1248 & 1282 & 1249 \\
\hline 0.0571 & 996 & 1347 & 1312 & 1342 & 1312 \\
\hline 0.1239 & 1116 & 1412 & 1390 & 1409 & 1390 \\
\hline 0.175 & 1171 & 1432 & 1416 & 1430 & 1416 \\
\hline 0.2482 & 1294 & 1447 & 1436 & 1446 & 1436 \\
\hline 0.3614 & 1321 & 1460 & 1453 & 1459 & 1453 \\
\hline 0.5601 & 1403 & 1470 & 1466 & 1469 & 1466 \\
\hline
\end{tabular}

Table 2: Average percentage values of $\mathrm{O}$-cresol with Carbon tetrachloride

\begin{tabular}{|c|c|c|c|c|c|}
\hline Conc(\%) & EXP & \%NOM & \%VV & \%RAO & \% IMP \\
\hline 0.0154 & 971 & -22.55 & -18.49 & -21.80 & -18.51 \\
\hline 0.0341 & 958 & -34.58 & -30.3 & -33.84 & -30.33 \\
\hline 0.0571 & 996 & -35.22 & -31.67 & -34.63 & -31.70 \\
\hline 0.0861 & 1081 & -28.13 & -25.49 & -27.71 & -25.52 \\
\hline 0.1239 & 1116 & -26.49 & -24.51 & -26.18 & -24.53 \\
\hline 0.2482 & 1294 & -11.8 & -10.98 & -11.72 & -10.99 \\
\hline 0.3614 & 1321 & -10.48 & -9.94 & -10.40 & -9.95 \\
\hline 0.5601 & 1403 & -4.77 & -4.53 & -4.73 & -4.53 \\
\hline APE & & -21.8 & -19.7 & -21.5 & -19.6 \\
\hline
\end{tabular}

Table 3: Experimental and mathematical values of ultrasound velocity for anisic aldehyde (AA) + methyl acetate (MA)

\begin{tabular}{|c|c|c|c|c|c|}
\hline Conc(\%) & EXP & NOM & VV & RAO & IMP \\
\hline 0.0685 & 1157 & 1145 & 1103 & 1171 & 1142 \\
\hline 0.1420 & 1200 & 1186 & 1104 & 1230 & 1179 \\
\hline 0.2210 & 1240 & 1227 & 1108 & 1285 & 1218 \\
\hline 0.3062 & 1281 & 1269 & 1118 & 1338 & 1259 \\
\hline 0.3984 & 1322 & 1312 & 1134 & 1387 & 1301 \\
\hline 0.4983 & 1361 & 1357 & 1160 & 1432 & 1345 \\
\hline 0.6071 & 1403 & 1402 & 1200 & 1471 & 1391 \\
\hline 0.7259 & 1445 & 1448 & 1263 & 1502 & 1440 \\
\hline
\end{tabular}

Table 4, illustrates the variation of percentage of deviation for binary mixture anisic aldehyde (AA) +methyl acetate (MA) at $303 \mathrm{~K}$. It is understood that percentage deviation is RAO $>$ NOM $>$ IMP $>$ VV. In Van-Deal and Van Geal relation only negligible deviation to experimental values is observed when compared to other methods. The experimentally measured ultrasonic velocity and the estimated ultrasonic velocity from various mathematical models for the binary liquid mixture anisic aldehyde 
(AA) + methyl acetate (MA) at five different concentrations at $303 \mathrm{~K}$ are presented in the Table 5 . Table 6 , illustrates the variation of percentage of deviation for binary mixture anisic aldehyde (AA) + ethylacetate (EA) at $303 \mathrm{~K}$. It is clear that the variation of percentage of deviation which is RAO $>\mathrm{IMP}>\mathrm{NOM}>\mathrm{VV}$. In VanDeal and Van-Geal relation only negligible deviation to experimental values is observed when compared to other methods.

Table 4: Average percentage values of anisic aldehyde (AA) + methyl acetate (MA)

\begin{tabular}{|c|c|c|c|c|c|}
\hline Conc(\%) & EXP & \%NOM & \%VV & \%RAO & $\%$ IMP \\
\hline 0.0685 & 1157 & -0.95 & -4.61 & 1.24 & -1.26 \\
\hline 0.1420 & 1200 & -1.14 & -7.99 & 2.54 & -1.68 \\
\hline 0.2210 & 1240 & -1.04 & -10.64 & 3.64 & -1.76 \\
\hline 0.3062 & 1281 & -0.87 & -12.71 & 4.46 & -1.70 \\
\hline 0.3984 & 1322 & -0.74 & -14.21 & 4.90 & -1.60 \\
\hline 0.4983 & 1361 & -0.33 & -14.74 & 5.20 & -1.16 \\
\hline 0.6071 & 1403 & -0.10 & -14.43 & 4.81 & -0.84 \\
\hline 0.7259 & 1445 & -0.19 & -12.60 & 3.97 & -0.37 \\
\hline 0.8563 & 1496 & -0.04 & -8.82 & 2.12 & -0.37 \\
\hline AVG & & -0.6 & -11.2 & 3.65 & -1.2 \\
\hline
\end{tabular}

Table 5: Experimental and mathematical values of ultrasound velocity for anisaldehyde (AA) + ethyl acetate (EA)

\begin{tabular}{|c|c|c|c|c|c|}
\hline Conc(\%) & EXP & NOM & VV & RAO & IMP \\
\hline 0.0832 & 1170 & 1160 & 1128 & 1184 & 1165 \\
\hline 0.1695 & 1215 & 1199 & 1138 & 1243 & 1208 \\
\hline 0.2592 & 1259 & 1239 & 1153 & 1298 & 1251 \\
\hline 0.3524 & 1303 & 1279 & 1172 & 1350 & 1293 \\
\hline 0.4494 & 1342 & 1321 & 1198 & 1397 & 1335 \\
\hline 0.5504 & 1381 & 1364 & 1232 & 1440 & 1377 \\
\hline 0.6557 & 1421 & 1407 & 1277 & 1476 & 1419 \\
\hline 0.7655 & 1462 & 1451 & 1337 & 1506 & 1461 \\
\hline 0.8802 & 1503 & 1497 & 1421 & 1528 & 1502 \\
\hline
\end{tabular}

Table 6: Average percentage values of anisic aldehyde (AA) + ethyl acetate $(\mathrm{EA})$

\begin{tabular}{|c|c|c|c|c|c|}
\hline Conc(\%) & EXP & \%NOM & \%VV & \%RAO & \% IMP \\
\hline 0.0832 & 1170 & -0.85 & -3.54 & 1.24 & -0.422 \\
\hline 0.1695 & 1215 & -1.30 & -6.27 & 2.31 & -0.562 \\
\hline 0.2592 & 1259 & -1.63 & -8.45 & 3.06 & -0.688 \\
\hline 0.3524 & 1303 & -1.77 & -10.01 & 3.60 & -0.726 \\
\hline 0.4494 & 1342 & -1.55 & -10.74 & 4.10 & -0.498 \\
\hline 0.5504 & 1381 & -1.26 & -10.81 & 4.22 & -0.275 \\
\hline 0.6557 & 1421 & -0.99 & -10.16 & 3.84 & -0.147 \\
\hline 0.7655 & 1462 & -0.70 & -8.50 & 2.99 & -0.076 \\
\hline 0.8802 & 1503 & -0.41 & -5.43 & 1.67 & -0.072 \\
\hline AVG & & -1.2 & -8.2 & 3 & -0.39 \\
\hline
\end{tabular}

\section{Conclusion}

The experimental ultrasonic velocity values of binary liquid mixtures such as O-Cresol with carbon tetrachloride, anisicaldehyde+methylacetate, anisicaldehyde+ethylacetateare compared with their theoretical ultrasonic velocity values for different concentrations at a temperature $303 \mathrm{~K}$. From these it may be concluded that the binary mixtures anisicaldehyde + methylacetate, anisicaldehyde + ethylacetateshowed Vandeal \& Vangeal relation as the best suitable method for calculating the speed of ultrasound waves in the liquid systems.

\section{References}

[1] Siddharthan N \& Jayakumar S (2015), Experimental and theoretical studies of ultrasonic velocity in binary liquid mixtures of toluene with benzene and carbon tetra chloride. Indian Journal of Science $13,145-154$

[2] Sandhya Sri P, Zareena Begum B \& Rambabu C (2013), Theoretical evaluation of ultrasonic velocities in binary liquid mixtures of Anisic aldehyde with some Esters at different temperatures using different theories and models. Journal of Thermodynamics and $\mathrm{Ca}$ talysis $4, \quad 1-8$.
[3] Vadamalar R, Mani D \& Balakrishnan R (2011), Ultrasonic study of binary liquid mixtures of Methyl methacrylate with Alcohols. Research Journal of Chemical Sciences 1, 79-82.

[4] Gayathri A \& Venugopal T (2015), Analysis of speed of acoustic waves in binary liquid system through mathematical and experimental methods. Indian Journal of Science 13, 1-4.

[5] Gayathri A \& Venugopal T (2015), A comparative analysis of ultrasound velocity in binary liquid systems of PPG by mathematical and experimental methods. Physics Procedia 70, 241-244.

[6] Venkatramanan K \& Arumugam V (2009), Miscibility studies of blends of PPG and PEG using viscosity technique. AIP Conference Proceedings 1004, 235-240. 